\title{
PENERAPAN PENDEKATAN EXPLICIT INSTRUCTION DENGAN TEKNIK SCAFFOLDING UNTUK MENINGKATKAN KEMAMPUAN PENALARAN MATEMATIS SISWA SMP
}

\author{
Resi Rismayanti ${ }^{2}$, Elsa Komala ${ }^{2}$ \\ ${ }^{1}$ University of Suryakancana \\ resirismayanti@gmail.com \\ ${ }^{2}$ University of Suryakancana \\ elsakomala@gmail.com
}

\begin{abstract}
The purpose of this research is to describe and study the influence of learning with explicit instruction approach with scaffolding technique to the students' mathematical reasoning ability. This study uses quasi experimental method, the design used is nonequivalent control group design. The experimental class acquired learning with the approach of instruction exsplisit and control class acquired conventional learning. The population of this study is the entire class VII one of Junior High School in Cianjur. As for the sample in this study selected as many as two classes from seven existing classes selected by purposive sampling technique. To obtain data of research result used instrument in the form of test of mathematical reasoning ability and questionnaire. Data processing improves the ability of mathematical reasoning using mann-whitney test. Based on data analysis, the result of research shows that the improvement of students 'mathematical reasoning ability using explicit instruction approach with scaffolding technique is better than improving students' mathematical reasoning ability using conventional approach, the improvement is in high category. The result of the questionnaire shows that students' attitude toward learning mathematics using explicit instruction approach with scaffolding technique is almost as positive.
\end{abstract}

Keywords: Explicit Instruction, Scaffolding, Mathematical Reasoning Ability.

\begin{abstract}
ABSTRAK
Tujuan penelitian ini adalah untuk mendeskripsikan dan mengkaji pengaruh pembelajaran dengan pendekatan explicit instruction dengan teknik scaffolding terhadap kemampuan penalaran matematis siswa SMP. Penelitian ini menggunakan metode kuasi eksperimen, desain yang digunakan adalah nonequivalent control grup design. Kelas eksperimen memperoleh pembelajaran dengan pendekatan exsplisit instruction dan kelas kontrol memperoleh pembelajaran konvensional. Populasi penelitian ini adalah seluruh kelas VII salah satu SMP Negeri di Cianjur. Adapun yang dijadikan sampel dalam penelitian ini dipilih sebanyak dua kelas dari tujuh kelas yang ada dipilih dengan teknik purposive sampling. Untuk memperoleh data hasil penelitian digunakan instrumen berupa tes kemampuan penalaran matematis dan angket. Pengolahan data peningkatan kemampuan penalaran matematis menggunakan uji mann-whitney. Berdasarkan analisis data, hasil penelitian menunjukkan bahwa peningkatan kemampuan penalaran matematis siswa yang menggunakan pendekatan explicit instruction dengan teknik scaffolding lebih baik dari pada peningkatan kemampuan penalaran matematis siswa yang menggunakan pendekatan konvensional, peningkatan yang terjadi ada pada kategori tinggi. Hasil angket menunjukkan bahwa sikap siswa terhadap pembelajaran matematika menggunakan pendekatan explicit instruction dengan teknik scaffolding adalah hampir seuruhnya positif.
\end{abstract}

Kata Kunci: Explisit Instruction, Scaffolding, Kemampuan Penalaran Matematis. 


\section{PENDAHULUAN}

Dalam Kurikulum 2013 (Hendriana dan Soemarmo, 2014: 7) mencantumkan tujuan pembelajaran matematika, salah satunya adalah menggunakan penalaran pada pola dan sifat, melakukan manipulasi matematika dalam membuat generalisasi, menyusun bukti, atau menjelaskan gagasan dan pernyataan matematika. Hal tersebut menunjukkan bahwa kemampuan penalaran matematis memiliki peran yang sangat penting dalam pembelajaran matematika. Oleh karena itu, kemampuan penalaran matematis harus dimiliki oleh setiap siswa. Namun pada kenyataannya pembelajaran di sekolah masih banyak yang belum mampu mengembangkan kemampuan penalaran matematis siswa, sehingga menyebabkan rendahnya kemampuan penalaran matematis siswa.

Kurangnya kemampuan penalaran matematis siswa dapat dilihat dari hasil survey yang dilakukan oleh lembaga-lembaga internasional seperti Trend in International Mathematics and Science Study (TIMSS) dan Program for International Student Assessment (PISA) (Murtiyasa: 2015) yang menempatkan indonesia pada posisi hampir terakhir diantara negara-negara yang di survey. Hasil survey tersebut menunjukkan kelemahan siswa pada kemampuan penalaran matematis siswa serta kemampuan menerapkannya dalam kehidupan sehari-hari.

Sejalan dengan Herman (2007) mengemukakan bahwa kemampuan siswa dalam penalaran, komunikasi dan koneksi matematis, serta pemecahan masalah dirasakan sangat kurang. Hal ini terlihat dari hasil pembelajaran siswa yang tersirat dalam hasil penelitian Sumarmo (2014) bahwa skor kemampuan siswa dalam pemahaman dan penalaran masih rendah.

Rendahnya kemampuan penalaran matematis siswa akan mempengaruhi kualitas belajar siswa, yang berdampak pula pada rendahnya prestasi belajar siswa di sekolah. Dengan demikian perlu adanya bantuan-bantuan khusus yang diberikan guru. Menurut Septiani (2013), bantuan pada siswa diberikan pada tahap awal pembelajaran kemudian mengurangi bantuan tersebut sampai siswa mendapat kesempatan belajar secara tanggung jawab, dalam penelitian ini bantuan yang diberikan berupa scaffolding yang merupakan bantuan-bantuan yang diberikan guru kepada siswa secara bertahap yang kemudian akan berkurang.

Sulistiawati (2014) dalam penelitiannya di SMP, berpendapat bahwa rendahnya kemampuan penalaran matematis siswa salah satunya disebabkan oleh pembelajaran matematika yang kurang melibatkan siswa. Dalam penelitian ini agar siswa terlibat aktif 
dalam pebelajaran matematika digunakanlah pendekatan explicit intruction yang menurut Archer dan Hughes (Huda, 2013: 186) merupakan pendekatan yang dirancang untuk mengembangkan belajar siswa berkaitan dengan pengetahuan deklaratif dan pengetahuan prosedural yang terstruktur dalam suatu pembelajaran dengan pola kegiatan yang bertahap, selangkah demi selangkah.

Berdasarkan uraian yang telah dikemukakan, akhirnya penelitian ini difokuskan pada penerapan pendekatan pembelajaran explicit instruction dengan teknik scaffolding guna untuk meningkatkan kemampuan penalaran matematis siswa SMP, dengan tujuan untuk mengetahui dan menelaah apakah peningkatan kemampuan penalaran matematis siswa dengan menggunakan pendekatan explicit instruction dengan teknik scaffolding lebih baik daripada peningkatan kemampuan penalaran matematis siswa dengan menggunakan pembelajaran konvensional, dan untuk mengetahui bagaimana sikap siswa terhadap pembelajaran matematika dengan menggunakan pendekatan explicit instruction dengan teknik scaffolding.

\section{Pendekatan Explisit Instructin}

Menurut Archer dan Hughes (Huda, 2013: 186), pendekatan explicit instruction adalah salah satu pendekatan mengajar yang dirancang khusus untuk menunjang proses belajar siswa. Pendekatan ini berkaitan dengan pengetahuan deklaratif dan pengetahuan prosedural yang terstruktur dan dapat diajarkan dengan pola kegiatan yang bertahap, selangkah demi selangkah. Strategi ini sering dikenal dengan model pengajaran langsung. Rosenshine \& Stevens (1984) mengemukakan bahwa explicit instruction merupakan pembelajaran langsung yang khusus dirancang untuk mengembangkan belajar siswa tentang pengetahuan prosedur dan pengetahuan deklaratif yang dapat diajarkan dengan pola selagkah demi selangkah.

Pendekatan explicit intruction merupakan pendekatan yang dirancang untuk mengembangkan belajar siswa berkaitan dengan pengetahuan deklaratif dan pengetahuan prosedural yang terstruktur dalam suatu pembelajaran dengan pola kegiatan yang bertahap, selangkah demi selangkah. Adapun tahapan atau sintaks pendekatan explicit instruction (Huda, 2013) yaitu: 1) Orientasi; 2) Presentasi; 3) Latihan terstruktur; 4) Latihan terbimbing; 5) Latihan mandiri; dan 6) Guru merencanakan kesempatan untuk melakukan instruksi lebih lanjut dengan berfokus pada situasi yang lebih kompleks atau kehidupan sehari-hari. 


\section{Teknik Scaffolding}

Septiani (2013: 42) scaffolding merupakan kegiatan memberikan bantuan kepada siswa pada tahap awal pembelajaran yang selanjutnya akan berkurang tingkatannya sampai siswa mampu bekerja secara tanggung jawab. Lipscomb et al., (2001) mendekskripsikan scaffolding sebagai sebuah bantuan yang diberikan guru atau teman yang memiliki kemampuan lebih. Dalam pembelajaran scaffolding guru membantu siswa agar mampu bekerja secara mandiri dan menguasai tugas atau konsep yang pada awalnya belum dipahami.

Teknik Scaffolding adalah sebuah teknik yang berupa bantuan-bantuan khusus yang diberikan guru kepada siswa secara bertahap. Dalam penelitian ini scaffolding akan dilakukan saat siswa sedang memecahkan suatu permasalahan dan saat pembuatan kesimpulan oleh siswa. Saffolding diberikan dalam bentuk pertanyaan, saran, dorongan maupun peringatan yang dapat mengarahkan siswa untuk memecahkan persoalan yang dihadapi. Adapun tingkatan pembelajaran scaffolding yaitu environment provisions, explaining, reviewing, restructuring, developing conceptual thinking.

\section{Kemampuan Penalaran Matematis}

Menurut Suherman dan Winataputra (1992) penalaran adalah proses berpikir yang dilakukan dengan suatu cara untuk menarik kesimpulan. kemampuan penalaran matematis membantu siswa dalam menyimpulkan dan membuktikan suatu pernyataan, membangun gagasan baru, sampai pada menyelesaikan masalah-masalah dalam matematika.

Kemampuan penalaran matematis adalah kemampuan siswa untuk menarik simpulan melalui proses mengidentifikasi/ menganalisis, mengajukan dugaan, menentukan, menghubungkan dan mengsintensis/ mengintegrasikan semua nformasi yang dilakukan dalam pemecahan masalah serta menyelesaikan masalah nonrutin.

Adapun indikator kemampuan penalaran matematis yang digunakan dalam penelitian ini antara lain: 1) Menyusun pembuktian langsung; 2) Memeriksa validitas argumen; 3) Memberikan penjelasan dengan model, fakta, sifat-sifat dan hubugan; 4) Menarik kesimpuan logis; 5) Memperkirakan jawaban dan proses solusi; dan 6) Menggunakan pola dan hubungan dalam menganalisis situasi. 


\section{METODOLOGI PENELITIAN}

Penelitian ini merupakan penelitian kuasi eksperimen. Populasi penelitian ini adalah siswa kelas VII salah satu SMP Negeri di Cianjur, dengan sampel dua kelas yakni VII-5 dan VII-6 pada sekolah tersebut dengan penentuan sampel dilakukan dengan menggunakan teknik "Purposive Sampling”, satu kelas eksperimen yang memperoleh pendekatan ekspilist istruction dengan teknik scaffolding dan satu kelas kontrol yang memperoleh pembelajaran konvensional.

Untuk mengukur peningkatan kemampuan penalaran matematis digunkana tes penalaran matematis yang terdiri dari 4 soal tes tertulis dalam bentuk uraian. Sebelum tes dijadikan instrumen penelitian, tes tersebut diukur validitas muka terkait dengan kejelasan bahasa atau redaksional dan kejelasan gambar atau representasi dan validitas isi terkait dengan materi pokok yang diberikan dan tujuan yang ingin dicapai serta aspek kemampuan yang diukur oleh ahli (expert). Langkah selanjutnya adalah tes diujicobakan untuk memeriksa validitas item, reliabilitas, daya pembeda dan tingkat kesukarannya. Uji coba dilakukan di SMP yang sama dengan tempat penelitian tetapi pada jenjang kelas yang lebih tinggi dari kelas yang akan dilakukan penelitian. Berdasarkan skor pretes dan postes dihitung peningkatannya yang terjadi pada masing-masing siswa menggunakan rumus gain ternormalisasi (N-Gain).

Angket diberikan kepada siswa kelas eksperimen pada akhir kegiatan berupa lembar pernyataan. Pernyataan yang diberikan kepada siswa bertujuan untuk mengetahui sikap siswa terhadap pembelajaran matematika menggunakan pendekatan explisit instruction. Angket menggunakan skala Likert dengan empat pilihan jawaban, yaitu: Sangat Setuju (SS), Setuju (S), Tidak Setuju (TS), Sangat Tidak Setuju (STS) dengan skor 4, 3, 2, dan 1 untuk pernyataan positif, untuk pernyataan negatif skor merupakan kebalikannya. Empat pilihan ini berguna untuk menghindari pendapat siswa pada suatu pernyataan yang diajukan sehingga pada skala pendapat siswa tidak digunakan opsi Netral (N). Skala konsep diri dibuat dalam bentuk pernyataan sebanyak 20 pernyataan yang terdiri dari 13 pernyataan positif dan 7 pernyataan negatif. 


\section{HASIL DAN PEMBAHASAN}

Peningkatan kemampuan penalaran matematis dalam penelitian ini dilihat dari besarnya gain ternormalisasi (N-Gain). Berdasarkan Tabel 1 ditemukan bahwa rerata NGain kelas eksperimen lebih tinggi daripada rerata N-Gain kelas kontrol.

Tabel 1. Skor Perbandingan rata-rata N-Gain kemampuan Penalaran Matematis

\begin{tabular}{ccccc}
\hline \multirow{2}{*}{ Kelas } & \multirow{2}{*}{ Jumlah Siswa } & \multicolumn{3}{c}{ Skor N-Gain } \\
\cline { 3 - 5 } & & Nilai Maksimum & Nilai Minimum & Rata-Rata \\
\hline Eksperimen & 31 & 1,00 & 0,33 & 0,867 \\
Kontrol & 31 & 0,86 & 0,25 & 0,375 \\
\hline
\end{tabular}

Pengujian peningkatan kemampuan penalaran matematis yang pembelajarannya menggunakan pendekatan explisit instruction dengan teknik scaffolding lebih baik daripada pembelajaran konvensional menggunakan uji mann-whitney. Sebelum melakukan uji mann-whitney terlebih dahulu dilakukan pengujian normalitas data kedua kelas dengan menggunakan Shapiro-Wilk. Hasil uji nomalitas adalah N-Gain kemampuan penalaran matematis siswa kelas eksperimen dan kelas kontrol masing-masing berasal dari populasi yang berdistribusi tidak normal dengan nilai Sig berturut-turut adalah 0,002 dan 0,000.

Tabel 2. Uji Mann-Whitney Data N.Gain

\begin{tabular}{lr}
\hline & \multicolumn{1}{c}{ Data N-Gain } \\
\hline Asymp. Sig. (2-tailed) & 0.000 \\
\hline
\end{tabular}

Untuk mengetahui signifikansi perbedaan rerata kedua kelas data digunakan uji statistic non parametrik, untuk pasangan data yang tidak beberdistribusi normal digunakan uji mann-whitney yang disajikan pada Tabel 2. dan diperoleh sig(2-tailed $)=0,000$. Nilai sig $(1$-tailed $)=1 / 2 \operatorname{sig}(2$-tailed $)$ berarti sig $(1$-tailed $)=1 / 2(0,000)=0,000$ (Widiarso, 2008). Selanjutnya diperoleh sig(1-tailed $)<0,05$. Berarti, peningkatan kemampuan penalaran matematis siswa kelas eksperimen lebih baik daripada peningkatan kemampuan penalaran matematis siswa kelas kontrol.

Pemberian perlakuan (treatment) pendekatan explicit instruction dengan teknik scaffolding kepada siswa di kelas eksperimen yang dapat membantu siswa lebih cepat memahami materi pembelajaran dan mampu mengembangkan kemampuan penalaran matematis. Salah satu yang mempengaruhi hal tersebut adalah dengan adanya arahanarahan dari guru secara explicit dan adanya scaffolding dalam proses pembelajaran, sehingga menghasilkan siswa aktif menalar dan bertanya dalam pembelajaran, serta siswa dapat menyelesaikan soal-soal yang diberikan lebih mudah. Hal ini juga ditunjukkan 
dengan hasil rata-rata $\mathrm{N}$-Gain kelas eksperimen adalah 0,8 yang berarti peningkatan kemampuan penalaran matematis siswa dalam interpretasi tinggi.

Untuk mengetahui sikap siswa yang terhadap pembelajaran matematika yang pembelajarannya dengen pendekatan explisit instruction dengan teknik scaffolding diperoleh rata-rata persentase sikap siswa berdasarkan hasil angket yang disajikan pada tabel 3:

\section{Tabel 3. Persentase Rata-rata Sikap Siswa}

\begin{tabular}{lcc}
\hline \multicolumn{1}{c}{ Aspek Sikap } & \multicolumn{2}{c}{ Persentase } \\
\cline { 2 - 3 } & Positif & Negatif \\
\hline $\begin{array}{l}\text { Sikap terhadap pembelajaran matematika menggunakan pendekatan } \\
\text { explicit instruction dengan teknik scaffolding }\end{array}$ & $90 \%$ & $10 \%$ \\
$\begin{array}{l}\text { Sikap terhadap soal-soal penalaran matematis menggunakan } \\
\text { pendekatan } \text { explicit instruction dengan teknik scaffolding }\end{array}$ & $81 \%$ & $19 \%$ \\
\hline
\end{tabular}

Dari Tabel 3. Diperoleh data bahwa rata-rata persentase sikap positif siswa adalah $85 \%$ hal ini menunjukkan bahwa hampir seluruhnya sikap siswa positif terhadap pembelajaran menggunakan pendekatan explicit instruction dengan teknik scaffolding. Hal ini diakibatkan oleh adanya demonstrasi guru, arahan-arahan dari guru, dan berdiskusi sebagai petunjuk. Sehingga siswa mampu bersikap positif terhadap materi pembelajaran serta terhadap permasalahan-permasalahan yang diberikan.

\section{KESIMPULAN}

Berdasarkan hasil penelitian, maka dapat simpulkan bahawa, peningkatan kemampan penalaran matematis siswa menggunakan pendekatan explicit instruction dengan teknik scaffolding lebih baik dari pada peningkatan kemampuan penalaran matemati siswa yang menggunakan pembelajran konvensional. Sikap siswa terhadap pembelajaran matematika menggunakan pendekatan explicit instruction dengan teknik scaffolding adalah sebagian besar positif.

\section{REFERENSI}

Hendriana, H \& Sumarmo, U. (2014) . Penilaian Pembelajaran Matematika. Bandung: PT. Refika Aditama.

Herman, T. (2007). Pembelajaran Berbasis Masalah untuk Meningkatkan Kemampuan Penalaran Matematis Siswa SMP. Cakrawala Pendidikan 26, (1), 41-62.

Huda, Miftahul. (2014). Model-Model Pengajaran dan Pembelajaran: Isu-isu Metodis dan Paradigmatis. Yogyakarta: Pustaka Pelajar. 
Lipscomb, L., Swanson, J., \& West, A. (2001). Scaffolding. .in M. Orey (Ed), Emerging perspectives on learning teaching and technology [e-Book]. Tersedia: http://projectts.coe.uga.edu/epltt/.

Murtiyasa, Budi. (2015). Tantangan Pembelajaran Matematika Era Global. Prosiding Seminar Nasional Matematika dan Pendidikan Matematika. Universitas Muhammadiyah Surakarta.

Rosenshine, Barak, \& Robert Stevens. (1984). "Classroom instruction in reading." Handbook of reading research 1 . Hal: 745-798.

Septiani, M. D. (2013). Pembentukkan Karakter dan Komunikasi Matematika melalui Model Problem Posing Berbantuan Scaffolding Materi Segitiga kelas VII. Skripsi pada FMIPA Universitas Negeri Semarang: tidak diterbitkan.

Suherman, E \& Winataputra, U. S. (1992). Strategi Beajar Mengajar Matematika. Jakarta: Dirjendikdasmen-Depdikbud.

Sulistiawati. (2014). Analisis Kesulitan Belajar Kemampuan Penalaran Matematis Siswa SMP pada Materi Luas Permukaan dan Volume Limas. Proceeding seminar nasional pendidikan matematika, sains dan TIK. STKIP Surya.

Widiarso, Wahyu. (2011). Uji Hipotesis Komparatif. Yogyakarta: FP UGM. 